\title{
Reduced exercise capacity in patients with tricuspid regurgitation after successful mitral valve replacement for rheumatic mitral valve disease
}

\author{
Peter H Groves, Neil P Lewis, Shahid Ikram, René Maire, Roger J C Hall
}

\begin{abstract}
Objective-To determine how severe tricuspid regurgitation influences exercise capacity and functional state in patients who have undergone successful mitral valve replacement for rheumatic mitral valve disease.

Design-9 patients in whom clinically significant tricuspid regurgitation developed late after mitral valve replacement were compared with 9 patients with no clinical evidence of tricuspid regurgitation. The two groups were matched for preoperative clinical and haemodynamic variables. Patients were assessed by conventional echocardiography, Doppler echocardiography, and a maximal treadmill exercise test in which expired gas was monitored by mass spectrometry.
\end{abstract}

Setting-University Hospital of Wales, Cardiff.

Subjects-18 patients who had been reviewed regularly since mitral valve replacement.

Main outcome measure-Objective indices of exercise performance including exercise duration, maximal oxygen consumption, anaerobic threshold, and ventilatory response to exercise.

Results-Mitral valve prosthetic function was normal in all patients and estimated pulmonary artery systolic pressure and left ventricular function were similar in the two groups. Right ventricular diameter (median (range) $5.0(4.3-5.6)$ v $3.7(3.0-5.4) \mathrm{cm}, \mathrm{p}<0.01)$ and the incidence of paradoxical septal motion $(9 / 9 v 3 / 9, p<0.01)$ were greater in the group with severe tricuspid regurgitation. Exercise performance-assessed by exercise duration $(6 \cdot 3(5 \cdot 0-10 \cdot 7) v$ $12 \cdot 7(7 \cdot 2-16 \cdot 0) \mathrm{min}, p<0.01)$, maximum oxygen consumption $(11.2(7 \cdot 3-17 \cdot 8) v$ $\left.17.7(11.8-21.4) \mathrm{ml} \mathrm{min}^{-1} \mathrm{~kg}^{-1}, \mathrm{p}<0.01\right)$, and anaerobic threshold $(8 \cdot 3(4 \cdot 6-11.4) v$ $\left.0.7(7 \cdot 3-15.5) \mathrm{ml} \mathrm{min}^{-1} \mathrm{~kg}^{-1}, \mathbf{p}<0.05\right)$ was significantly reduced in the group with severe tricuspid regurgitation. The ventilatory response to exercise was greater in patients with tricuspid regurgitation (minute ventilation at the same minute carbon dioxide production (41.0 $(29.9-59.5)$ v $33.6 \quad(26.8-39 \cdot 3) \quad 1 / \mathrm{min}$, p $<0.01$ ).
Conclusions-Clinically significant tricuspid regurgitation may develop late after successful mitral valve replacement and in the absence of residual pulmonary hypertension, prosthetic dysfunction, or significant left ventricular impairment. Patients in whom severe tricuspid regurgitation developed had a considerable reduction in exercise capacity caused by an impaired cardiac output response to exercise and therefore experienced a poor functional outcome. The extent to which this was attributable to the tricuspid regurgitation itself or alternatively to the consequences of right ventricular dysfunction was not clear and requires further investigation.

Successful mitral valve replacement for rheumatic mitral valve disease is accompanied in most patients by a sustained symptomatic improvement. ${ }^{1-3}$ Continuation or return of limiting symptoms may indicate the presence of prosthetic valve failure, impairment of left ventricular function, persistent pulmonary hypertension, or the development of important aortic valve disease. All may lead to a rise in right heart pressures and the subsequent development of functional tricuspid regurgitation. We found that severe tricuspid regurgitation can develop in the absence of these factors and that it can also be responsible for a poor functional outcome. Attention has been paid in the past to the importance of right ventricular function as a determinant of exercise capacity in heart failure. ${ }^{45}$ In chronic left ventricular failure, exercise capacity seems to correlate with resting right ventricular ejection fraction ${ }^{5}$ and pulmonary vascular resistance. ${ }^{6}$ Although not previously studied, the presence of severe tricuspid regurgitation is likely to be associated with a reduced right ventricular output and would also be expected to compromise exercise capacity in the absence of left ventricular impairment.

Clinical assessment was a poor guide to true functional state after valve replacement ${ }^{7}$ and the criteria applied are by their nature subjective with poor interobserver reproducibility. ${ }^{8}$ Exercise testing, incorporating expired gas analysis, is now well established as a safe, reliable, and reproducible method of studying the pathophysiological response to exercise in 
patients with heart failure. ${ }^{910}$ It is also valuable as a method of assessing accurately the severity of cardiac disease and correlating this with the extent of functional limitation. ${ }^{112}$

The aim of this study was to establish by exercise testing with expired gas analysis how the presence of severe tricuspid regurgitation influenced exercise capacity and functional state in patients who had undergone successful mitral valve replacement for rheumatic mitral valve disease.

\section{Patients and methods}

Eighteen patients were studied; nine (eight women, one man) had developed clinically significant tricuspid regurgitation late after successful mitral valve replacement for rheumatic mitral valve disease. Their mean age was 59 years (range 48-67). All patients had experienced an initial symptomatic improvement after operation but they described the return of limiting symptoms when clinical signs of tricuspid regurgitation became apparent. Clinically significant tricuspid regurgitation was diagnosed in the presence of a raised jugular venous pressure with prominent $\mathrm{cv}$ wave, pulsatile hepatomegaly, and fluid retention requiring intensive diuretic treatment. Nine patients (eight women, one man) who had also undergone mitral valve replacement for rheumatic mitral valve disease were chosen as a closely matched control group. Their mean age was 62 years (range 56-67). When we selected these patients we attempted to match clinical, preoperative haemodynamic, operative, and current echocardiographic indices as closely as possible (tables 1 and 2). None had clinical signs of tricuspid regurgitation or a history of postoperative fluid retention. All patients in both groups were in atrial fibrillation.

Patients were questioned about current cardiac symptoms, and functional capacity was assessed according to the New York Heart Association (NYHA) classification. During clinical examination we noted the presence or absence of physical signs suggesting tricuspid regurgitation. The jugular venous pressure was examined with the patient sitting at $45^{\circ}$. The mean of the venous waveforms was estimated clinically and the height measured in centimetres above the sternal angle. This value was used to derive an indirect measurement of right atrial pressure. Results of preoperative cardiac catheterisation and the details of valve surgery were obtained from the patient records.

\section{ECHOCARDIOGRAPHY}

Standard transthoracic echocardiography was performed with a Hewlett Packard 77510A scanner in all patients. Cross sectional, $M$ mode, and Doppler echocardiography with continuous wave, pulsed wave, and colour flow Doppler were performed in all standard views. The examination was performed with all subjects in the left lateral decubitus and supine positions. $M$ mode echocardiograms were recorded at a paper speed of $100 \mathrm{~mm} / \mathrm{s}$. Variables derived from the $M$ mode echocardiogram and Doppler recordings were measured for five consecutive beats and a mean value was calculated.

The left ventricular dimensions were recorded in the long axis view as the greatest dimensions of the left ventricle obtained at the level of the mitral valve prosthesis. The minor axis dimensions were measured between the endocardial surfaces of the posterior wall and interventricular septum. The end diastolic dimension (EDD) was taken at the peak of the $R$ wave of the simultaneously recorded electrocardiogram. The end systolic dimension (ESD) was defined as the minimum distance separating the endocardial surfaces at the peak upward anterior motion of the posterior ventricular wall. Fractional shortening was calculated by the following formula:

$$
\text { FS }(\%)=\frac{\text { LVEDD }- \text { LVESD }}{\text { LVEDD }} \times 100
$$

The right ventricular end diastolic dimension was measured as the distance between the endocardial surfaces of the right ventricle at the $\mathrm{R}$ wave of the simultaneously recorded electrocardiogram. The direction of septal motion in early systole was recorded and judged to be either normal or paradoxical.

Prosthetic valve function was studied by visual inspection of the cross sectional echocardiogram and by Doppler assessment. Continuous wave Doppler signals of diastolic mitral flow velocity were recorded and an estimate of mitral valve area was derived from the pressure half time. Mitral regurgitation was sought by pulsed wave echocardiography and colour flow Doppler mapping in apical and left parasternal views.

Tricuspid regurgitation was detected in all 18 subjects and was apparent with both continuous wave and colour flow Doppler. Doppler recordings of maximal velocity were obtained from the apical and left parasternal views and continuous wave Doppler signals were considered optimal once the maximum clearly defined spectral envelope was achieved. The peak velocity $(v)$ of the tricuspid regurgitation jet was used to calculate the systolic tricuspid valve gradient from a modified Bernoulli equation:

$$
\text { TV gradient }(\mathrm{mm} \mathrm{Hg})=4 \mathrm{v}^{2}
$$

The systolic pressure gradient across the tricuspid valve represents the difference between the right ventricular and right atrial systolic pressures. The right ventricular systolic pressure (and also pulmonary artery systolic pressure) can therefore be estimated if the pressure gradient and right atrial pressure are known. ${ }^{13}$ Right atrial pressure was estimated by adding $5 \mathrm{~cm}$ to the mean clinical jugular venous pressure assessment ${ }^{14}$ and converted to $\mathrm{mm} \mathrm{Hg}$ by dividing the right atrial pressure in centimetres by 1.3 to take account of the relative densities of mercury and blood at physiological temperatures. ${ }^{15}$

The severity of tricuspid regurgitation was estimated echocardiographically and graded as mild, moderate, or severe. This semiquantitative assessment was made on the basis of the width of the regurgitant jet and the distance to 
which it extended into the right atrium, as detected by colour flow and pulsed wave Doppler. Tricuspid regurgitation was graded as mild if the regurgitant jet was narrow and extended into the right atrium no further than one third the length of the inter-atrial septum and severe if the jet was broad, reached the posterior atrial wall, and was detected in the hepatic vein. Intermediate findings were judged to reflect moderate tricuspid regurgitation.

\section{EXERCISE TESTING}

Symptom limited maximal exercise testing was performed according to the Weber treadmill protocol, ${ }^{9}$ which is a progressive exercise protocol designed for heart failure patients. Subjects continued their normal medication on the day of exercise testing. The heart rate and electrocardiogram were recorded continuously and a standard 12 lead electrocardiogram was performed every minute. Blood pressure was recorded by mercury sphygmomanometer every two minutes. Respiratory gas analysis was performed during exercise by mass spectrometry (Airspec 2000, Biggin Hill, UK) by means of the argon dilution technique. ${ }^{16} \mathrm{Min}-$ ute oxygen consumption $\left(\dot{\mathrm{Vo}}_{2}, \mathrm{ml} \mathrm{min}^{-1} \mathrm{~kg}^{-1}\right)$, minute carbon dioxide production $\left(\dot{\mathrm{V}}_{2}\right.$, $\mathrm{ml} \mathrm{min}{ }^{-1} \mathrm{~kg}^{-1}$ ), and minute ventilation ( $\dot{\mathrm{V}} \mathrm{E}$, $1 / \mathrm{min}$ ) were measured every 15 seconds. Exercise duration and maximal oxygen consumption (defined as the mean oxygen consumption during the final 30 seconds of exercise) were recorded. The anaerobic threshold was determined by computerised analysis of a curve fitting model of the relation between oxygen consumption and carbon dioxide production. ${ }^{17}$ The ventilatory response to exercise was determined from linear regression analysis of the relation between minute ventilation and carbon dioxide production. ${ }^{18} 19$

\section{ANALYSIS OF RESULTS}

All data are reported as medians and ranges. Results obtained for the two groups were compared by a Mann-Whitney test for continuous variables and a Fisher exact probability test for non-continuous variables. A p value of $<0.05$ was regarded as statistically significant.

\section{Results}

\section{CLINICAL}

Table 1 summarises clinical details of the two groups. They were well matched for age, sex, and duration of symptoms before operation and were studied at similar intervals postoperatively. All patients were in atrial fibrillation and none had significant coronary artery disease or aortic valve disease. The preoperative haemodynamic findings were similar in the two groups, as were the type and size of mitral valve prostheses implanted (table 1). None of the patients with clinically significant tricuspid regurgitation had an abnormal right atrial ' $v$ ' wave at preoperative cardiac catheterisation, while one patient in the control group had a right atrial ' $v$ ' wave up to $12 \mathrm{~mm}$ $\mathrm{Hg}$. Mild tricuspid regurgitation was detected by palpation at operation in four of those who subsequently developed clinically significant tricuspid regurgitation but was absent in all patients in the control group.

\section{ECHOCARDIOGRAPHY}

Table 2 summarises the echocardiographic findings. All the indices of left ventricular function were similar in the two groups. None of the patients in either group had evidence of prosthetic valve dysfunction and none had developed significant aortic valve disease. The estimated pulmonary artery systolic pressure was not significantly higher in patients with severe tricuspid regurgitation, but the right ventricular diameter and the incidence of paradoxical septal motion were significantly greater $(\mathrm{p}<0.01)$ in this group.

The tricuspid valve was found to be thickened in six patients with clinically significant tricuspid regurgitation and in eight patients in the control group. Tricuspid valve motion, however, remained free in all those studied and none had cross sectional echocardiographic features that suggested valve stenosis or valve prolapse. The degree of tricuspid regurgitation was judged to be severe in six patients and moderate in three of the patients with clinically significant tricuspid regurgitation. In contrast, regurgitation was found to be moderate in five patients and mild in four patients in the control group.

Table 1 Clinical, preoperative cardiac catheterisation, and surgical details of the two patient groups (median (range))

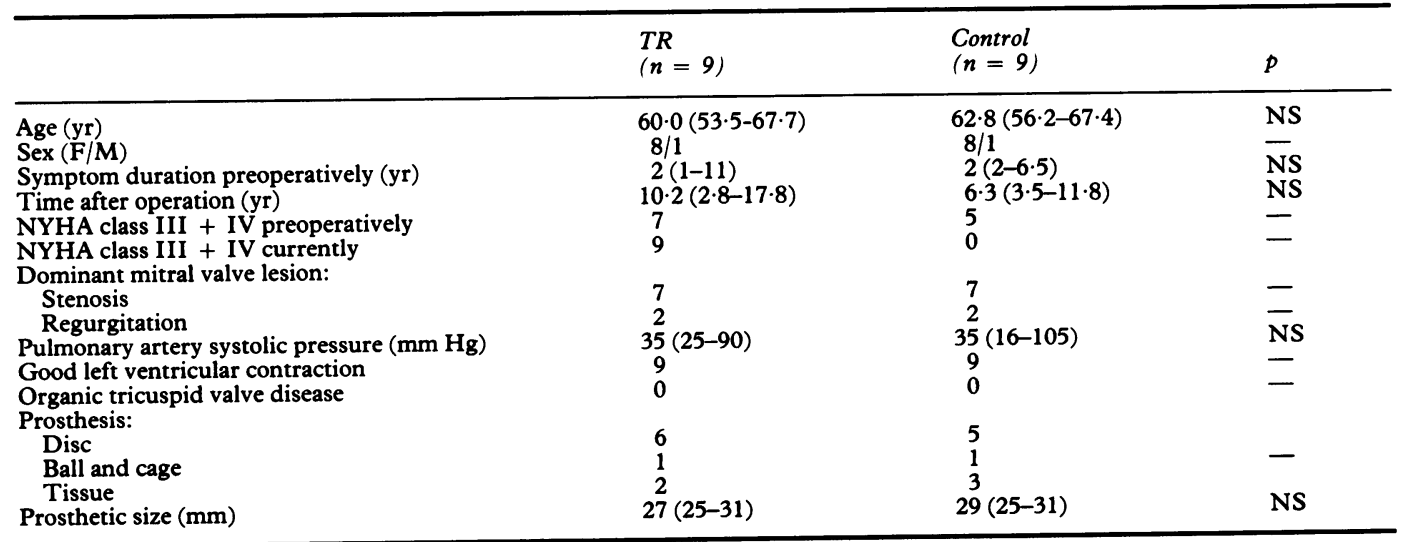

TR, tricuspid regurgitation. 
Table 2 Echocardiographic results (median (range))

\begin{tabular}{lccc}
\hline Variable & $\begin{array}{l}T R \\
(n=9)\end{array}$ & $\begin{array}{l}\text { Control } \\
(n=9)\end{array}$ & $p$ \\
\hline LVEDD $(\mathrm{cm})$ & $5 \cdot 1(2 \cdot 3-7 \cdot 9)$ & $4 \cdot 3(3 \cdot 7-5 \cdot 5)$ & NS \\
LVESD $(\mathrm{cm})$ & $3 \cdot 8(1 \cdot 3-6 \cdot 4)$ & $3 \cdot 2(2 \cdot 6-4 \cdot 5)$ & NS \\
FS $(\%)$ & $23(16-33)$ & NS & $<0.01$ \\
RV diameter $(\mathrm{cm})$ & $5 \cdot 0(4 \cdot 3-5 \cdot 6)$ & $3 \cdot 7(3.0-5 \cdot 4)$ & $<01$ \\
Paradoxical septal motion & 9 & 3 & NS \\
Pulmonary artery systolic pressure (mm Hg) & $33(31-53)$ & $27(16-67)$ & NS \\
MV area $\left(\mathrm{cm}^{2}\right)$ & $2 \cdot 7(1.8-3 \cdot 4)$ & $1.9(1 \cdot 2-4 \cdot 2)$ & \\
\hline
\end{tabular}

FS, fractional shortening; LVEDD, left ventricular end diastolic diameter; LVESD, left ventricular end systolic diameter; MV mitral valve; $R V$, right ventricle; $T R$, tricuspid regurgitation.

Table 3 Ventilatory changes and indices of performance during exercise (median (range))

\begin{tabular}{|c|c|c|c|}
\hline Variable & $\begin{array}{l}T R \\
(n=9)\end{array}$ & $\begin{array}{l}\text { Control } \\
(n=9)\end{array}$ & $p$ \\
\hline $\begin{array}{l}\text { Exercise duration (min) } \\
\text { RER: }\end{array}$ & $6 \cdot 3(5 \cdot 0-10 \cdot 7)$ & $12 \cdot 7(7 \cdot 2-16 \cdot 0)$ & $<0.01$ \\
\hline $\begin{array}{l}\text { Rest } \\
\text { Maximum } \\
\mathrm{VE} / \mathrm{VCO}_{2} \text { slope } \\
\text { Minute ventilation at } \mathrm{CO}_{2} \text { production of } 11 / \mathrm{min}(1 / \mathrm{min}) \\
\text { Maximum increase in } \mathrm{SBP}\left(\mathrm{mm}^{-1} \mathrm{~g}\right) \\
\text { Maximum increase in } \mathrm{HR}\left(\mathrm{min}^{-1}\right) \\
\mathrm{VO}_{2} \text { max }\left(\mathrm{ml} \min ^{-1} \mathrm{~kg}^{-1}\right) \\
\text { Anaerobic threshold }\left(\mathrm{ml} \mathrm{min}^{-1} \mathrm{~kg}^{-1}\right)\end{array}$ & $\begin{array}{l}0.86(0 \cdot 72-0 \cdot 88) \\
1.03(0 \cdot 93-1 \cdot 06) \\
37.9(28 \cdot 5-57 \cdot 5) \\
41.0(29 \cdot 9-59 \cdot 5) \\
8.0(-18-30) \\
40(11-78) \\
11 \cdot 2(7 \cdot 3-17 \cdot 8) \\
8.3(4 \cdot 6-11 \cdot 4)\end{array}$ & $\begin{array}{l}0.81(0 \cdot 74-0 \cdot 88) \\
1 \cdot 06(0.95-1 \cdot 22) \\
30 \cdot 8(22 \cdot 9-33 \cdot 4) \\
33 \cdot 6(26 \cdot 8-39 \cdot 3) \\
22 \cdot 0(2-50) \\
74(20-77) \\
17 \cdot 7(11 \cdot 8-21 \cdot 4) \\
10 \cdot 7(7 \cdot 3-15 \cdot 5)\end{array}$ & $\begin{array}{l}\text { NS } \\
\text { NS } \\
<0.01 \\
<0.01 \\
<0.05 \\
0.05 \\
<0.01 \\
<0.05\end{array}$ \\
\hline
\end{tabular}

$\mathrm{HR}$, heart rate; $\mathrm{RER}$, respiratory exchange ratio $\left(\mathrm{CO}_{2}\right.$ produced: $\mathrm{O}_{2}$ consumed); SBP, systolic blood pressure; $\dot{\mathrm{VE}} / \hat{\mathrm{V}} \mathrm{CO}_{2}$ slope is derived by linear regression and expresses the relation between ventilation $(\nabla \mathrm{E})$ and carbon dioxide production $\left(\mathrm{V}_{2} \mathrm{CO}_{2}\right)$ during exercise; $\mathrm{VO}_{2}$ max, maximum oxygen consumption.

EXERCISE TESTING

Resting respiratory exchange ratio was normal in all patients and increased during exercise (table 3). The mean respiratory exchange ratio at peak exercise in both groups exceeded 1.0, indicating maximal exercise and the onset of anaerobic metabolism, with production of lactate and therefore a rise in carbon dioxide production relative to the amount of oxygen consumed. An exaggerated hyperpnoeic response to exercise was seen in patients with clinically significant tricuspid regurgitation but not in the control group. The linear relation between minute ventilation and carbon dioxide production (total ventilatory response) was significantly steeper (figure), so that minute ventilation was increased relative to the same carbon dioxide production (table 3). Patients with tricuspid regurgitation had a blunted haemodynamic response to exercise with significantly smaller rises in both heart rate and systolic blood pressure (table 3). Exercise duration, maximum oxygen consumption, and anaerobic threshold were significantly lower in patients with tricuspid regurgitation than in the controls (table 3).

\section{Discussion}

Our results show that the presence of clinically significant tricuspid regurgitation after successful mitral valve replacement for rheumatic mitral valve disease was associated with a considerable impairment of exercise capacity and a poor functional outcome. We were careful to compare the exercise performance of patients with severe tricuspid regurgitation with that of a well matched control group to eliminate other variables that were likely to influence exercise capacity. In particular, we specifically chose patients in both groups with well preserved resting left ventricular function on echocardiography, in order to concentrate on the influence exerted by the right heart on exercise performance. Although this method of left ventricular assessment is relatively crude, our principal object was to minimise differences between the two groups rather than to establish whether or not left ventricular function was normal in all patients. Pulmonary artery systolic pressure was also similar in the two groups and none of the patients had prosthetic dysfunction or important aortic valve disease. We conclude that the substantial differences in exercise capacity seen between the groups could only be explained by the presence or absence of tricuspid regurgitation. An exaggerated hyperpnoeic response to exercise ${ }^{19}$ and

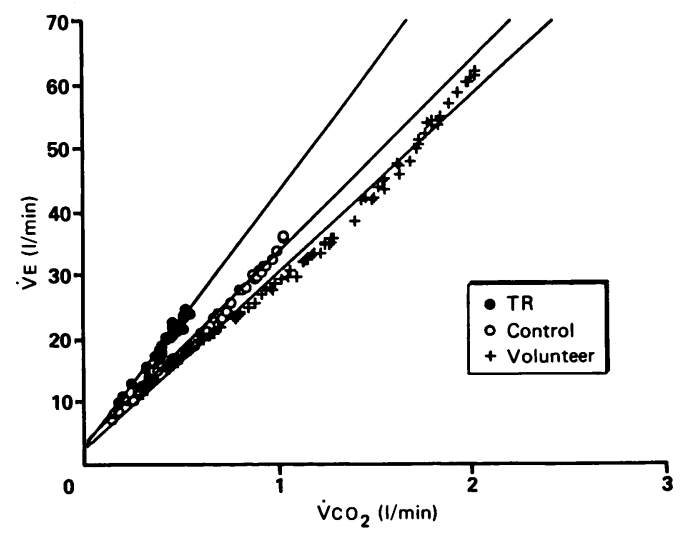

Relation between minute ventilation and carbon dioxide production during exercise for representative (median) patients from the two groups studied and a healthy volunteer. 
reductions in maximal oxygen consumption ${ }^{20}$ and anaerobic threshold ${ }^{20} 21$ reflect an impaired overall cardiac output response to exercise in patients with heart failure. This is also presumably the mechanism by which exercise capacity is reduced in patients with tricuspid regurgitation-that is, by limiting the increase in right ventricular cardiac output that can be achieved during exercise. Our findings, however, do not enable us to determine whether this is because of a progressively failing right ventricle, of which tricuspid regurgitation is merely a marker, or whether a large tricuspid regurgitant fraction is itself primarily responsible for a reduction in forward flow. In either case, our results corroborate evidence suggesting that events in the right heart are important in determining exercise capacity. ${ }^{4-6}$

It is not clear why significant tricuspid regurgitation developed in these patients. Echocardiography showed thickening of the tricuspid valve in two thirds of the patients with clinically significant tricuspid regurgitation; but this was also a common finding among those in the control group and was never accompanied by abnormal cusp motion. Thickening of the tricuspid valve is a non-specific finding at echocardiography and the czis sectional echocardiogram is generally able to identify when it is accompanied by valve stenosis and is a feature of organic rheumatic tricuspid valve disease. ${ }^{22}$ In the absence, therefore, of organic tricuspid valve disease, we assume that tricuspid regurgitation is functional in these patients. Neither significant pulmonary arterial nor venous hypertension were present and it is likely, therefore, that severe functional tricuspid regurgitation develops either as a result of progressive right ventricular dysfunction or as a result of persistent dilatation of the tricuspid valve annulus. Because we studied these patients when the consequences of severe tricuspid regurgitation were likely to be advanced, it is difficult to determine which is most likely. Right ventricular dysfunction could develop as a result of tricuspid regurgitation but the reverse is also true. This difficult question has important therapeutic implications. Surgical correction of tricuspid regurgitation may be of some benefit if persistent annular dilatation is the dominant underlying abnormality, while it may be no help or even detrimental if annular dilatation is secondary to right ventricular dysfunction.

King et al retrospectively analysed their results of surgery for tricuspid regurgitation that developed late after mitral valve replacement. $^{23}$ of 32 patients, 14 had no evidence of prosthetic valve dysfunction or significant aortic valve disease; however, they did not comment on indices of left ventricular function or pulmonary artery systolic pressure in these patients. Tricuspid valve replacement was performed in 11 patients while three underwent tricuspid valve annuloplasty. Only four patients, however, improved by at least one NYHA class, while three patients died in the early postoperative period because of a low cardiac output and six died during the follow- ing six years. One patient remained in NYHA class IV. They concluded that tricuspid regurgitation developing late after mitral valve replacement in their patients was a manifestation of right ventricular failure and that restoring tricuspid valve competence was of little benefit. Though their results are certainly disappointing, we cannot conclude that tricuspid valve surgery has no part in the management of this heterogeneous group. It may be, for example, that patients with a relatively low pulmonary artery systolic pressure and well preserved left ventricular function would experience better results from tricuspid valve repair or replacement. Certainly, before dismissing the role of surgery, it would be necessary prospectively to study the benefits of correcting tricuspid regurgitation, both on functional state and on outcome, in patients with severe tricuspid regurgitation but without pulmonary hypertension, left ventricular dysfunction, or prosthetic valve failure.

Of perhaps more importance, given the apparent high mortality of reoperation on the tricuspid valve $e^{23}$ and the considerable functional limitation that we showed in these patients, is that much is to be gained in attempting to reduce the likelihood of severe tricuspid regurgitation developing after mitral valve replacement. This may best be achieved by the accurate detection and correction of important tricuspid regurgitation at initial surgery. Tricuspid regurgitation is a common finding in patients with advanced mitral stenosis or regurgitation and may be present in more than $50 \%$ of those requiring mitral valve replacement. ${ }^{24}$ Traditional methods of assessment both preoperatively and at the time of surgery are imprecise. ${ }^{26}$ Haemodynamic measurements are of limited value in assessing the severity of tricuspid regurgitation ${ }^{242627}$ and digital examination of the amount of tricuspid regurgitation present at operation is influenced by many variables which make it unreliable. ${ }^{28}$ These methods of pre and per operative assessment were used in our group of patients and it is possible that the degree of tricuspid regurgitation was underestimated. Czer et al suggest that intraoperative colour flow mapping is a more reliable and reproducible method of assessing the severity of tricuspid regurgitation and of selecting patients who need surgical repair of the tricuspid valve. ${ }^{26}$ They report a favourable comparison between this technique and right ventricular angiography, which has previously been regarded as the "gold standard" but which is rarely performed. Intraoperative colour flow mapping can certainly be performed easily and may be of benefit both in assessing the severity of tricuspid regurgitation and also in judging the adequacy of tricuspid valve repair.

Although accurate assessment of tricuspid regurgitation is now possible, its subsequent surgical management remains controversial. Braunwald et al originally suggested that nonorganic tricuspid regurgitation would regress after adequate correction of left sided lesions, ${ }^{29}$ but it is now recognised that this is often not the case. ${ }^{263031}$ Failure to correct significant tricus- 
pid regurgitation at the time of surgery may be an important factor that leads to subsequent progressive right heart failure and worsening tricuspid regurgitation. There is much debate, however, about the best method of preventing this. Tricuspid valve replacement is usually reserved for those with either very severe tricuspid regurgitation or organic tricuspid valve disease with accompanying stenosis. ${ }^{3032}$ In those without organic tricuspid valve disease or with less severe tricuspid regurgitation, annuloplasty may be performed. Deloche et al established that in functional tricuspid regurgitation five sixths of the annular dilatation occurs at the base of the anterior and posterior leaflets, with only one sixth occurring at the insertion of the septal leaflet. ${ }^{33} \mathrm{Kay}$ et al ${ }^{34}$ described a method of annuloplasty of the tricuspid valve involving plication of the posterior leaflet, producing a bicuspid valve but eliminating only $50 \%$ of the annular dilatation. ${ }^{35}$ This was accompanied by high and unpredictable failure rates. ${ }^{3035}$ The method of De Vega, ${ }^{36}$ however, leads to a uniform plication of the anterior and posterior leaflets because circumferential sutures are placed around the annulus; this results in a semicircular deformation of the tricuspid orifice. Alternatively, insertion of a prosthetic valve ring was described by Carpentier et al ${ }^{37}$ with the shape of the ring conforming to that of the tricuspid valve and producing a predictable correction with a normal valve orifice and usually excellent valve function. Rivera $e t$ al compared the use of De Vega annuloplasty and the Carpentier ring and found better results with the Carpentier ring. ${ }^{38}$ The Carpentier ring procedure produced a better anatomical repair ${ }^{28}$ and by the use of interrupted sutures distributed the holding force over the entire ring, producing a more effective and durable reduction in tricuspid regurgitation. ${ }^{26}$ Whichever approach is adopted it seems that the long term prognosis is often poor ${ }^{28}{ }^{29} \mathrm{McG}$ rath et al report that among 530 patients undergoing a tricuspid valve procedure during surgery for valvar heart disease, $14.7 \%$ died in hospital, while $40 \%$ of those who survived the original procedure died during late follow up. ${ }^{39}$ The presence of significant tricuspid regurgitation usually indicates advanced valve disease and it is possible that earlier surgery would reduce the necessity for intervention at the tricuspid valve and improve the overall long term results of surgery.

In conclusion, we showed that patients who develop significant tricuspid regurgitation late after successful mitral valve replacement for rheumatic mitral valve disease have a considerable reduction in exercise capacity resulting in a poor functional outcome. Exercise testing with expired gas analysis indicates that this is attributable to an impaired cardiac output response to exercise resulting from failure of the right ventricle or from the influence that tricuspid regurgitation itself has in limiting a rise in right ventricular cardiac output. Residual pulmonary hypertension was not present and left ventricular function was well preserved in these patients. Given the relatively high risk of re-operation involving the tricuspid valve and the degree of functional limitation shown in these patients, efforts should be made to reduce the likelihood of severe tricuspid regurgitation developing after mitral valve replacement. This may best be achieved by the accurate intraoperative detection and correction of important tricuspid regurgitation at the time of initial surgery. If surgery were considered at an earlier stage of valve disease functional tricuspid regurgitation might become less of a problem.

1 Cohn LH, Allred EN, Cohn LA, et al. Early and late risk of mitral valve replacement. A 12 year concomitant comparison of the porcine bioprosthetic and prosthetic disc mitral ison of the porcine bioprosthetic and prosthetic disc
valves. $J$ Thorac Cardiovasc Surg 1985;90:872-80.

2 Sethia B, Turner MA, Lewis S, et al. Fourteen years experiençe with the Björk-Shiley tilting disc prosthesis. Thorac Cardiovasc Surg 1986;91:350-61.

3 Bloomfield P, Kitchin AH, Wheatley DJ, Walbaum PR, Lutz W, Miller HC. A prospective evaluation of the Björk-Shiley, Hancock and Carpentier-Edwards hear valve prostheses. Circulation 1986;73:1213-22.

4 Engler R, Ray R, Higgins CB, et al. Clinical assessment and follow up of functional capacity in patients with chronic congestive cardiomyopathy. Am J Cardiol 1982;49: 1832-7.

5 Baker BJ, Wilen MM, Boyd CM, Dinh H, Franciosa JA Relation of right ventricular ejection fraction to exercise capacity in chronic left ventricular failure. Am J Cardiol capacity in chroni

6 Franciosa JA, Baker BJ, Seth L. Pulmonary versus systemic haemodynamics in determining exercise capacity of patients with chronic left ventricular failure. Am Heart 1985;110:807-13.

7 Gilmour DG, Spiro SG, Raphael MJ, Freedman S. Exercise tests before and after heart valve replacement. $\mathrm{Br} J \mathrm{Di}$ Chest 1979;70:185-94.

8 Goldman L, Hasmoto B, Cook F, Lascalzo A. Comparative reproducibility and validity of systems for assessing cardiovascular functional class. Circulation 1981;64:1227 34

9 Weber KT, Kinasewitz GT, Janicki JS, Fishman AP Oxygen utilization and ventilation during exercise in patients with chronic cardiac failure. Circulation 1982;65:1213-23.

10 Wilson JR, Ferraro N. Exercise intolerance in patients with chronic left heart failure: relation to oxygen transport and ventilatory abnormalities. Am J Cardiol 1983;51:1358-63.

11 Lipkin DP, Perrins J, Poole-Wilson PA. Respiratory gas exchange in the assessment of patients with impaired exchange in the assessment of patients with

12 Franciosa JA. Exercise testing in chronic congestive heart failure. Am J Cardiol 1984;53:1447-50.

13 Yock PG, Popp RL. Non-invasive estimation of right ventricular systolic pressure by Doppler ultrasound in patients with tricuspid regurgitation. Circulation 1984;70:657-62.

14 Braunwald E, ed. Heart disease: a textbook of cardiovascular medicine. Philadelphia: WB Saunders, 1988:19.

15 Currie PJ, Seward JB, Chan K-L, et al. Continuous wave Doppler determination of right ventricular pressure: simultaneous Doppler-catheterisation study in 127 patients. J Am Coll Cardiol 1985;4:750-6.

16 Davies N, Denison DM. Measurement of metabolic gas exchange and minute volume by mass spectrometry alone. Respir Physiol 1979;36:261-7.

17 Beaver WL, Wasserman K, Whipp BJ. A new method for detecting anaerobic threshold by gas exchange. $J$ App Physiol 1986;60:2020-7.

18 Lewis NP, Fox KAA, Henderson AH. In congestive heart failure (CHF) exercise air spectroscopy provides a sensitive marker

19 Buller NP, Poole-Wilson PA. Mechanism of the increased ventilatory response to exercise in patients with chronic ventilatory response to exercise in patients
heart failure. Br Heart J 1990;63:281-3.

20 Weber KT, Wilson JR, Janicki JS, Likoff MJ. Exercise testing in the evaluation of the patient with chronic cardiac testing in the evaluation of the patient with chronic cardic

21 Opasich C, Cobell F, Riccardi G, et al. Does the study of anaerobic metabolism give quantitative information on anaerobic metabolism give quantitative information on left ventricular dysfunction
$1988 ; 9$ (suppl F):17-21.

22 Hall RJC, Julian DG. Diseases of the cardiac valves. New York: Churchill Livingstone, 1989:249.

23 King MR, Schaff HV, Danielson GK, et al. Surgery for tricuspid regurgitation late after mitral valve replacement. Circulation 1984;70 (suppl I):I-193-7.

24 Cohen ST, Sell JE, McIntosh CL, Clark RE. Tricuspid regurgitation in patients with chronic, pure mitral regurgitation. II. Non-operative management, tricuspid valve annuloplasty and tricuspid valve replacement. $J$ Thorac Cardiovasc Surg 1987;94:488-97.

25 Goldman ME, Guarino T, Fuster V, Mindich B. The 
necessity for tricuspid valve repair can be determined by intra-operative 2D echocardiography. $J$ Thorac Cardiovasc Surg 1987;94:542-50.

26 Czer LSC, Maurer G, Bolger A, et al. Tricuspid valve repair. Operative and follow-up evaluation by Doppler colour

27 Cairnes KB, Klostor FE, Bristow JD, et al. Problems in the Cairnes $\mathrm{KB}, \mathrm{Klostor} \mathrm{FE}$, Bristow JD, et al. Problems in the
haemodynamic diagnosis of tricuspid insufficiency. $\mathrm{Am}$ heart $J$ 1968;75:173-9.

28 Mullany CJ, Gersh BJ, Orszulak TA, et al. Repair of tricuspid valve insufficiency in patients undergoing double (aortic and mitral) valve replacement. Perioperative mortality and long term ( 1 to 20 years) follow-up in 109 patients. $J$ Thorac Cardiovasc Surg 1987;94:740-8.

29 Braunwald NS, Ross J Jr, Morrow AG. Conservative management of tricuspid regurgitation in patients undergoing mitral valve replacement. Circulation $1967 ; 35$ (Pt 2):163-9.

30 Pluth JR, Ellis FH Jr. Tricuspid insufficiency in patients undergoing mitral valve replacement: conservative management, annuloplasty, or replacement. J Thorac Cardiovasc Surg 1969;58:484-9.

31 Duran CMG, Pomar JL, Colman T, et al. Is tricuspid valve repair nece

32 Breyer RH, McClenathan JH, Michaelis LL, McIntosh CL, Morrow AG. Tricuspid regurgitation: a comparison of non-operative management, tricuspid annuloplasty and tricuspid valve replacement. $J$ Thorac Cardiovasc Surg 1976;72:862-70.

33 Deloche A, Guerinon J, Fabiani JN, et al. Etude anatomique des valvulplasties rhumatismales tricuspidiennes. d'annuloplastie. Ann Chir Thorac Cardiovasc 1973; d'annulop

34 Kay JH, Maselli-Campagna G, Tsiyi HK. Surgical treatment of tricuspid insufficiency. Ann Surg 1965;162:53-8. 35 Grondin P, Meere C, Limet R, et al. Carpentier's annulus Grondin P, Meere C, Limet R, et al. Carpentier's annulus
and De Vega's annuloplasty. J Thorac Cardiovasc Surg and De Vega's
$1975 ; 70: 852-9$.

36 De Vega NG. La annuloplastia selectiva regulabe y permanente: una técnicia original para el tratamiento de la insuficienci tricuspide. Rev Esp Cardiol 1972;25:555-6.

37 Carpentier A, Deloche A, Dauptain J, et al. A new reconstructive operation for correction of mitral and tricuspid insufficiency. J Thorac Cardiovasc Surg 1971;61:1-13.

38 Rivera R, Duran E, Ajuria M. Carpentier's flexible ring versus De Vega's annuloplasty. A prospective randomized
study. $J$ Thorac Cardiovasc Surg 1985;89:196-202.

39 McGrath LB, Gonzalez-Lavin L, Bailey BM, et al. Tricuspid valve operations in 530 patients. Twenty-five year pid valvent of early and late phase events. $J$ Thorac Cardiovasc Surg 1990;99:124-33.

\section{PLANTS IN CARDIOLOGY}

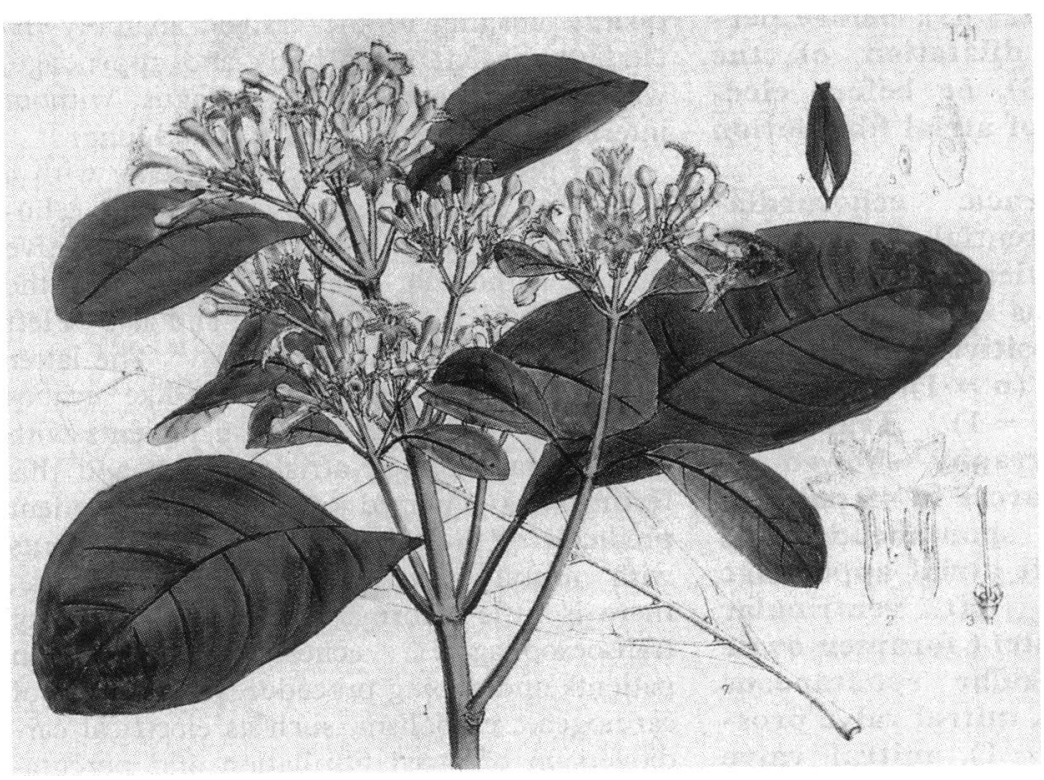

Cinchona ledgeriana Moens ex Trimen. Bentley R, Trimen H. Medicinal plants. Vol 2. London: Churchill, 1880:141.

\section{Quinine and quinidine}

The bark of the South American tree Cinchona (Rubiaceae) contains quinine, and also quinidine-isolated by Pasteur in 1853. Its use in treating fevers was learnt in Peru by Spanish missionaries who in 1630 brought the bark to Europe where its value in malaria was discovered. In 1749 Jean-Baptiste de Sénac wrote "Long and rebellious palpitations have ceded to this febrifuge". In the nineteenth century quinine was used to augment digitalis therapy, and quinidine was described as "das opium des herzens". But the definitive use of quinidine in arrhythmias came about only because of an astute observation in 1912 by a patient of Professor Karel F Wenckebach who then related the story in the Journal of the American Medical Association (1923;81:472-4). The patient was a man with attacks of atrial fibrillation who said that "being a Dutch merchant used to good order in his affairs he would like to have good order in his heart business also and asked why there were heart specialists if they could not abolish this very disagreeable phenomenon ... . he knew himself how to get rid of his attacks and as I did not believe him he promised to come back next morning with a regular pulse, and he did".

The man had found by chance that when he took one gram of quinine during an attack it reliably halted it in 25 minutes: otherwise it would last for 2-14 days. Quinine was used then not only in malaria but also as a nonspecific remedy for minor ailments as aspirin is today. Wenckebach often tried quinine again but he succeeded in only one other patient. However, it led W Frey in Berlin to study all four cinchona alkaloids in atrial fibrillation and in 1918 he showed that quinidine was the most effective. In 1920 Thomas Lewis put forward his famous hypothesis of circus movement and proposed that quinidine restored normal rhythm by closing the gap between the crest and wake of the circus wave.

The family Rubiaceae is huge with over 10000 species worldwide. Emetine comes from ipecacuanha and caffeine from coffee but there are no other medicinal species. One genus has the splendid name of Captaincookia. Quinine and quinidine are still obtained naturally, from the species Cinchona ledgeriana grown commercially in the tropics.

A HOLLMAN 